\title{
Are we profiling patients with fibromyalgia?
}

\author{
Monique Camerlain MD FRCPC ${ }^{1}$, Geneviève Myhal PhD²
}

$\mathrm{O}^{\mathrm{fi}}$ ffender profiling is a method of identifying the perpetrator of a crime based on an analysis of the nature of the offense and the manner in which it was committed. Humans have always had a fascination with the concept of profiling criminals, and the origins of profiling can be traced back to as early as the Middle ages, with the inquisitors trying to 'profile' heretics (1).

During the 1880s, Thomas Bond, a medical doctor, tried to profile the personality of Jack the Ripper. Bond, a police surgeon, assisted in the autopsy of Mary Kelly. In his notes, dated November 10, 1888, he mentioned the sexual nature of the murders coupled with elements of apparent misogyny and rage (1).

At once both exciting and controversial, the profiling of criminal minds has entered our collective consciousness by routes as disparate as the heightened airport security following September 11, 2001, and, more insidiously, profiling's representation within popular culture. Examples include Patricia Cornwell's best-selling books starring detective Kay Scarpetta; television series such as Wire in the Blood, CSI and Criminal Minds; and movies including The Silence of the Lambs, Copycat, Suspect Zero, Mindhunters and Citizen X (1,2). Civil rights advocates are against the use of racial profiling tactics by the police, arguing that the disproportionate number of convicted visible minorities is due to 'racial profiling'. Terrorist profiling is also questioned, and has recently led to a lawsuit against the airline industry (3).

Does profiling also exist in health care? Does prejudice deprive some patients of compassion, the opportunity to build a positive therapeutic relationship with their health care providers and, ultimately, of proper treatment? A recent editorial in Pain Research EO Management raises the question "Do we care about chronic pain patients?" (4). Considering common attitudinal challenges tied to everyday popular negative profiling (eg, ageism, sexism and racism), let us consider the specific case of patients with fibromyalgia and ask "Is 'fibroism' thriving in spite of new and reliable evidence regarding the possibility of achieving positive health outcomes with these patients?" A recent New York Times controversy offers a platform to further this discussion.

A front-page article by reporter Alex Berenson (dated January 14, 2008) entitled "Drug Approved: Is Disease Real?" (5) casts doubt on the existence and validity of fibromyalgia. This viewpoint has drawn numerous comments and stirred a controversy regarding possible prejudice against chronic pain patients and, more specifically, against patients with fibromyalgia.

Numerous letters to the editor by patients, nonprofit health organizations and physicians have made the point that, disease or not, the pain felt by patients is very real. In a letter to the editor posted on January 17, 2008 (6), one patient replies that "Millions of people suffer from the physical pain and crippling fatigue associated with fibromyalgia. We are not hypochondriacs, but sick people in search of a cure, and of more compassionate medical care."

As stated by Judith Paice $\mathrm{PhD}$ RN, the President of the American Pain Society (7), "Scepticism and cynicism are nothing new to those who suffer from chronic pain, especially fibromyalgia syndrome... Writer Alex Berenson delivered a cruel blow to anyone with fibromyalgia by characterizing the disease as a phantom disorder promoted by the pharmaceutical industry to sell prescription medications. The article could give credence to and re-energize cynics and skeptics who have stigmatized pain patients, especially those who deny coverage for pain management."

As physicians, we strive to provide patient-centred care and place great value on therapeutic relationship-building and effective communication with patients. However, we know that $30 \%$ to $80 \%$ of patients' expectations are not met in routine primary care visits in spite of health care providers' best efforts (8). Considering the impact of chronic pain on individuals' lives, families and friends, as well as the burden of illness on the health sector and the economy, let us not let cynicism, scepticism and prejudice stand as barriers to care and empathy for patients with fibromyalgia. As with all patients, let us do our best to meet their needs and expectations and to relieve their pain and suffering.

CONFLICTS OF INTEREST: Dr Monique Camerlain has served on an advisory board and as a lecturer on fibromyalgia with Pfizer Canada Inc.

The most fundamental principle of medicine is love. - Paracelsus

\section{REFERENCES}

1. Offender profiling. $<$ http://en.wikipedia.org/wiki/Offender_profiling $>$ (Version current at May 29, 2009).

2. Gopal AA, Bursztajn HJ. Offender profiling: An introduction to the sociopsychological analysis of violent crime. <http://ajp. psychiatryonline.org/cgi/content/full/163/3/559-a> (Version current at May 29, 2009).

3. Zalman A. Profiling Passengers Pros \& Cons. $<$ http://terrorism.about. com/od/issuestrends/i/Profiling.htm $>$ (Version current at May 29, 2009).

4. Lynch ME. Do we care about people with chronic pain? Pain Res Manage 2008;13:463.

5. Berenson E. Drug Approved. Is Disease Real? <http://www.nytimes. com/2008/01/14/health/14pain.html?_r=1\&em\&ex=1200459600\&en= bac45d5aff5a17d7\&ei=5087\%0A $>$ (Version current at May 29, 2009).

6. Disease or Not, the Pain Is Very Real. <http://www.nytimes. $\mathrm{com} / 2008 / 01 / 17 /$ opinion/117disease.html?pagewanted=1\&_r=1> (Version current at May 29, 2009).

7. Paice J. From the American Pain Society. <http://www.fmaware.org/ site $/$ News2 page $=$ NewsArticle\&id=6835> (Version current at May 29, 2009).

8. Epstein RM, Mauksch L, Carroll J, Jaén CR. Have you really addressed your patient's concerns? Fam Pract Manag 2008;15:35-40.

${ }^{1}$ Rheumatic Diseases Unit, Sherbrooke University Medical Centre, Sherbrooke; ${ }^{2}$ Axdev Group, Brossard, Quebec

Correspondence: Dr Monique Camerlain, Clinique Belvedere, 2235 rue Galt Ouest, Suite 210, Sherbrooke, Quebec J1K 1 K6 


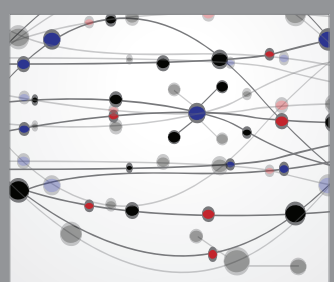

The Scientific World Journal
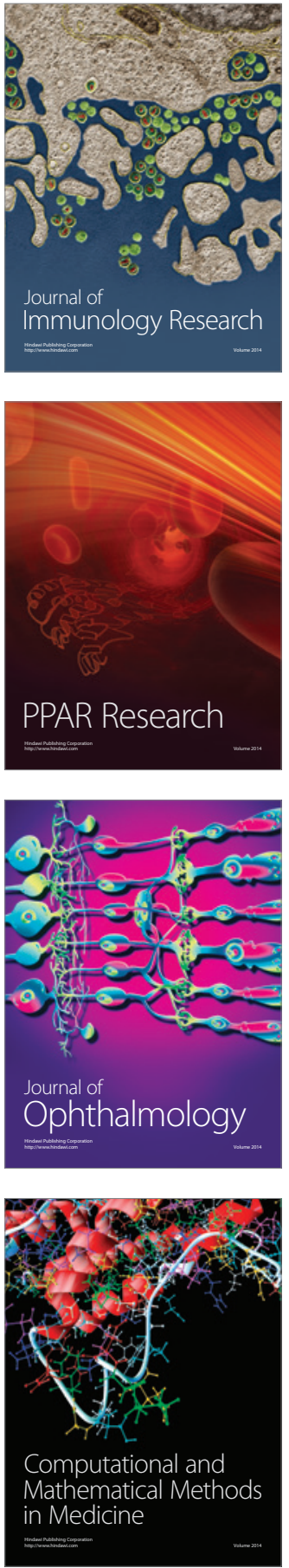

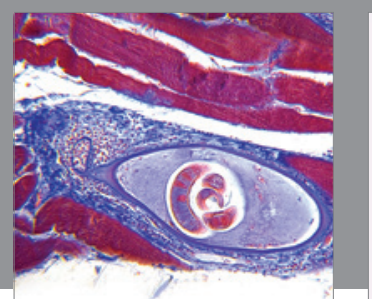

Gastroenterology Research and Practice

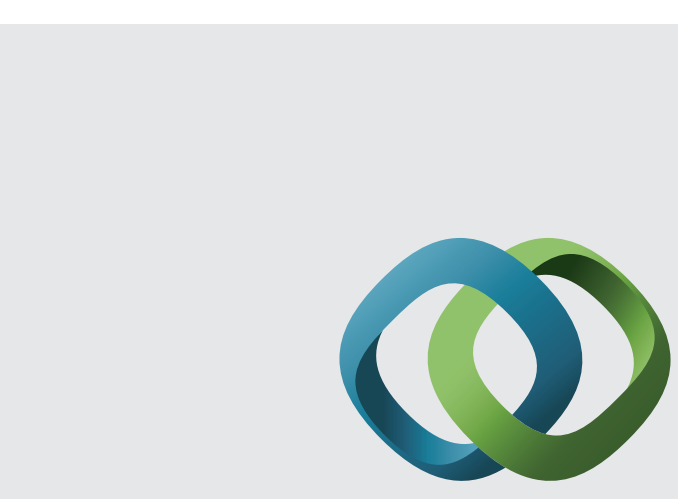

\section{Hindawi}

Submit your manuscripts at

http://www.hindawi.com
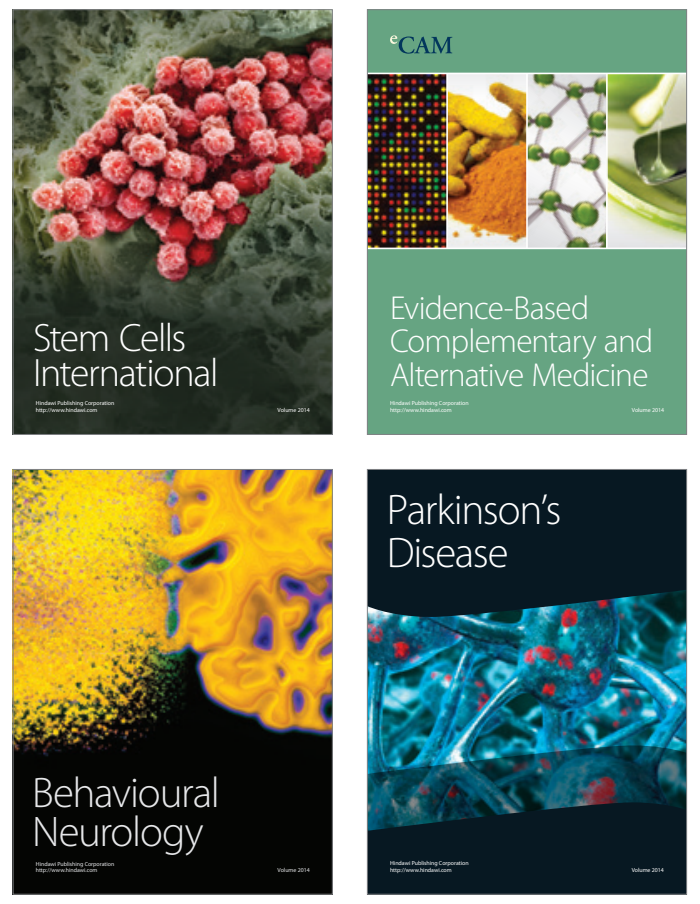
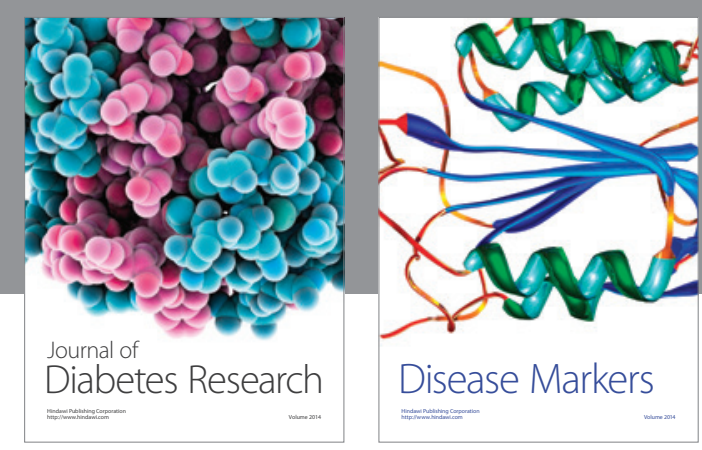

Disease Markers
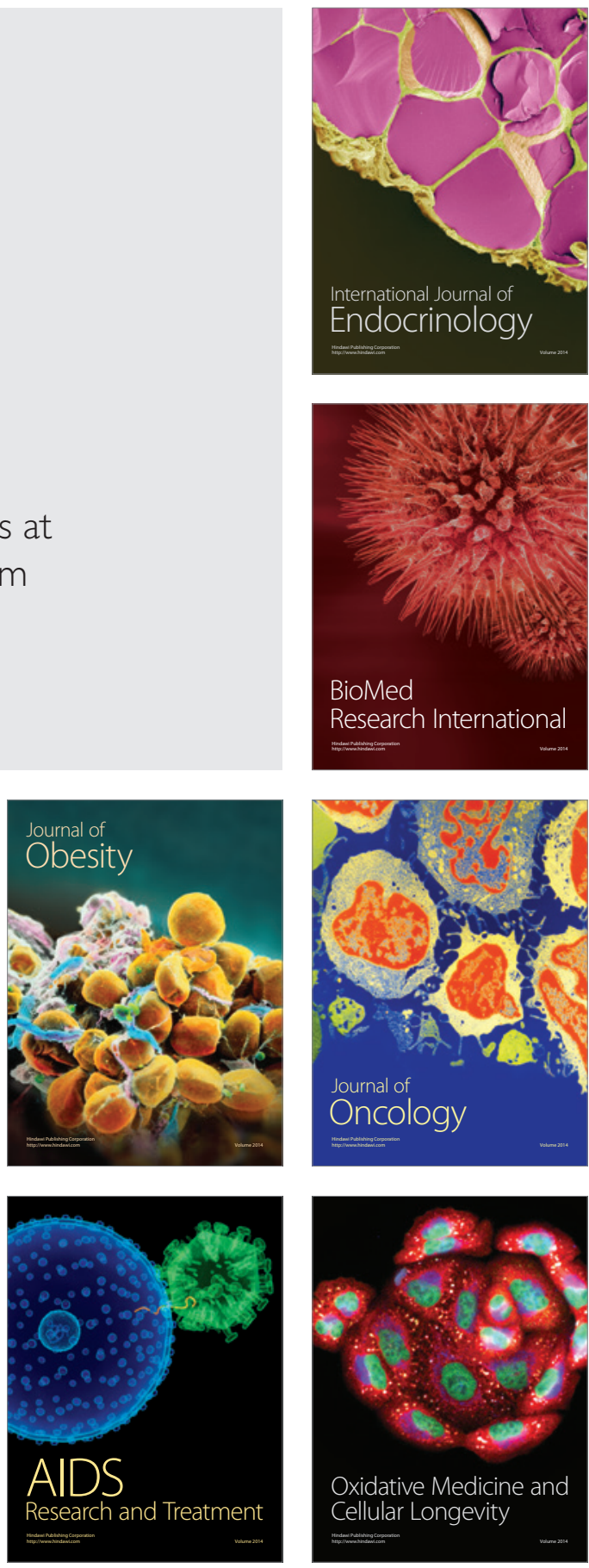